\title{
Which Etiology Causes the Most Severe Acute Pancreatitis?
}

\author{
Paul Georg Lankisch, ${ }^{*, 1}$ Christine Assmus, ${ }^{1}$ \\ Diana Pflichthofer, ${ }^{1}$ Karl Struckmann, ${ }^{2}$ and Dirk Lehnick ${ }^{3}$ \\ Departments of ${ }^{7}$ Internal Medicine and ${ }^{2}$ Radiology, Municipal Clinic of Lüneburg, Lüneburg, Germany; \\ and ${ }^{3}$ Institute for Statistics and Econometrics, Georg-August University of Göttingen, Göttingen, Germany
}

\section{Summary}

Background. The aim of the study was to define the prognostic role of etiology in the course of acute pancreatitis.

Methods. The study involved 208 consecutive patients with a first attack of acute pancreatitis. Etiology was biliary in $81(39 \%)$ patients and alcohol abuse in $69(33 \%)$; other etiologies were present in $16(8 \%)$, and etiology remained unknown in $42(20 \%)$. Etiology was correlated with the following parameters of severity of the disease: days in an intensive care unit (ICU); total hospital stay (THS); Ranson, Imrie, and Balthazar scores (contrast-enhanced computed tomography [CT] within $72 \mathrm{~h}$ of admission); indication of artificial ventilation, dialysis, or surgery; development of pancreatic pseudocysts; mortality.

Results. Alcoholic etiology correlated significantly more frequently than other subgroups with necrotizing pancreatitis, need for artificial ventilation, and development of pancreatic pseudocysts. For the other parameters, there were no significant differences between the etiologies.

Conclusion. Patients with alcohol-induced acute pancreatitis should be given special attention because of the higher incidence of necrotizing pancreatitis and necessity for artificial ventilation. Whether the pronounced frequency of pseudocysts in alcoholics suggests progression to chronic pancreatitis has to be clarified in follow-up studies.

Key words: Acute pancreatitis; etiology; prognostic parameters; computed tomography; pseudocysts; mortality.

\section{Introduction}

Acute necrotizing pancreatitis with its high mortality rate is a life-threatening gastrointestinal disorder requiring special intensive care and therapy unavailable in nonspecialized hospitals. One reason for the high mortality rate is late transfer to specialized centers because the extent of severity has

Received March 3, 1999; Revised May 25, 1999; Accepted July 8, 1999.

*Author to whom all correspondence and reprint requests should be addressed: Medizinische Klinik, Staedtisches Klinikum Lueneburg, Boegelstrasse 1, D-21339 Lueneburg, Germany. not been detected early enough on admission (I). With present diagnostic methods, early detection is not easy. At least $24 \mathrm{~h}$ are needed for a proper evaluation of physical examination results and $48 \mathrm{~h}$ for correctly interpreting prognostic scores $(2,3)$. Ultrasound gives limited results owing to meteorism and ileus, and expensive contrast-enhanced computed tomography (CT) is not available everywhere. An immediate and cheaper diagnostic tool could be the determination of etiology. Etiology can be quickly found out for evaluation of the severity of the disease by asking case history questions, e.g., prior alcohol and/or drug consumption, gallstone attacks, and examination, including ultrasound of the gall- 
Table I

Comparison of Parameters of the Severity of Acute Pancreatitis and Etiological Groups in 208 Patients

\begin{tabular}{|c|c|c|c|c|}
\hline \multirow[b]{2}{*}{ Parameters } & \multicolumn{3}{|c|}{ Etiologies } & \multirow[b]{2}{*}{ Unknown, $n=42$} \\
\hline & Biliary, $n=81$ & Alcohol. $n=69$ & Other, $n=16$ & \\
\hline ICU (median) & $5 \mathrm{~d}$ & $5 \mathrm{~d}$ & $3 \mathrm{~d}$ & $6 d$ \\
\hline THS (median) & $26 d$ & $23 d$ & $23 \mathrm{~d}$ & $20 \mathrm{~d}$ \\
\hline Ranson $>5$ points & $3(4 \%)$ & $5(7 \%)$ & $-\quad-$ & $4(10 \%)$ \\
\hline Imrie $>3$ points & $10(12 \%)$ & $5(7 \%)$ & $-\quad-$ & $5(12 \%)$ \\
\hline Balthazar > 4 points & $10(12 \%)^{a}$ & $20(29 \%)^{b}$ & $2(13 \%)$ & $9(21 \%)$ \\
\hline Artificial ventilation & $5(6 \%)$ & $13(19 \%)^{\circ}$ & $1 \quad(6 \%)$ & $4(10 \%)$ \\
\hline Dialysis & $-\quad-$ & $1(1 \%)$ & $-\quad-$ & $3(7 \%)$ \\
\hline Surgery & $5(6 \%)$ & $11(16 \%)$ & $1(6 \%)$ & $4(10 \%)$ \\
\hline Pseudocysts & $8(10 \%)$ & $19(28 \%)^{d}$ & $2(13 \%)$ & $3(7 \%)$ \\
\hline Mortality & $7(9 \%)$ & $7(10 \%)$ & $1(6 \%)$ & $4(10 \%)$ \\
\hline
\end{tabular}

Biliary versus nonbiliary acute pancreatitis: " $p=0.034$; alcohol vs nonalcohol: $" p=0.026 ; " p=0.018 ;{ }^{\prime \prime} p=0.001$.

bladder and the common bile duct. The aim of our study was thus to define the prognostic role of etiology for the severity of acute pancreatitis.

\section{Patients and Methods}

The study involved 208 consecutive patients admitted from 1988 to 1995 with a first attack of acute pancreatitis to the Municipal Hospital of Lüneburg, the only hospital serving the county of Lüneburg (population 150,000). The diagnosis was based on characteristic signs and symptoms, elevated serum amylase and/or lipase levels, and contrast-enhanced $C T$ results obtained $<72 \mathrm{~h}$ after admission and scored according to Balthazar et al. (4). All patients with prior unexplained episodes of abdominal pain and/or acute pancreatitis, and all patients with signs of chronic pancreatitis on subsequent imaging procedures were excluded.

Etiology of acute pancreatitis was assumed to be owing to alcohol abuse when the patient or her/his relatives reported a regular alcohol consumption of $>120 \mathrm{~g}$ pure ethanol in the form of beer, wine, or schnapps/d, or an alcohol cxcess immediately before the acute attack. Biliary-induced acute pancreatitis was assumed when gallstones were found on subsequent ultrasound examination, CT, or endoscopic retrograde cholangiopancreatography (ERCP). Other causes of acute pancreatitis were endoscopic procedures (ERCP), trauma, or drugs. In the remaining cases, etiology was classified as unknown.
Etiology of acute pancreatitis in the 208 patients was biliary in $81(39 \%)$, alcohol abuse in $69(33 \%)$, and other in $16(8 \%)$ patients. In the remaining 42 $(20 \%)$ cases, etiology remained unknown.

The following parameters of severity were evaluated in regard to etiology: days spent in the intensive care unit (ICU); total hospital stay (THS); Ranson (2), Imrie (3), and Balthazar (4) scores (contrast-cnhanced CT within $72 \mathrm{~h}$ after admission): indication for artificial ventilation, dialysis, or surgery (necrosectomy); development of pancreatic pseudocysts; mortality. Ranson scores $>5$ points, Imrie $>3$, and Balthazar $>4$ were featured, since they indicate severe acute pancreatitis $(2-4)$ and pancreatic necrosis (4). The modified Ranson (5) score was used in cases of biliary acute pancreatitis. For statistical analysis, Fisher's exact test was used.

\section{Results}

Patients with alcohol-induced acute pancreatitis needed more often artificial ventilation and surgery (necrosectomy), mostly for septic complications, although the latter did not reach the level of significance. Otherwise, there were no significant differences in the correlation between etiology and severity of the disease (Table 1). Pancreatic pseudocysts were significantly more frequently observed in patients with necrotizing than with interstitial acute pancreatitis (Balthazar score $>4$ vs $<4$ ). Accordingly, patients with alcohol-induced acute pancreatitis 
developed pseudocysts significantly more frequently than patients with nonalcohol-induced disease. For the other parameters, there were no signiticant differences between the etiologies (Table 1).

\section{Discussion}

$\Lambda$ contrast-enhanced $C T$ is recommended for patients with clinically suspected severe acute pancreatitis between days 3 and 10 after admission (6). This may be recommended especially in patients with alcohol abuse, since we show that in this etiological subgroup, the incidence of pancreatic necrosis is higher than in others.

Furthermore, patients with alcohol-induced acute pancreatitis should be monitored more intensively for the development of respiratory insufficiency than others. since the incidence of the indication for artificial ventilation in alcoholics is high. Whether this is owing to the higher incidence of smokers in this group with a presumably higher subsequent damage to the lung prior to acute pancreatitis is unknown. but should be the subject of future prospective studies. Some investigations have shown that alcohol abuse per sc has a negative effect on the lung $(7.8)$.

Whether the higher incidence of pancreatic pscudocysts in patients with alcohol-induced acute pancreatitis is an indication of slow progression from acute to chronic pancreatitis is as yet unknown and should al so be considered in subsequent prospective studies.

There is only one other similar study from a tertiary referral center that has dealt with the influence of etiology of acute pancreatitis on the severity of the disease, using contrast-enhanced CT investigation of the pancreas (9). No differences concerning $C T$ results were found in patients with alcohol- and biliary-induced acule pancreatitis and a third group in which other etiologies and idiopathic acute pancreatitis were considered together.

The marked differences in CT results that we found for alcohol-induced acute pancreatitis may be explained by the following two factors: First, in the other study, CT was performed within $24 \mathrm{~h}$. Since a prior study by the same group has shown that in $97 \%$ of the patients with necrotizing acute pancreatitis $72 \mathrm{~h}$ are needed to detect the development of pancreatic necrosis $(10)$. it may be that patients who developed pancreatic necrosis later than $24 \mathrm{~h}$ were not included (9). Second. our study is from a sec- ondary referral center representing more an epidemiological situation since it is the only hospital serving our area, whereas the other study was performcd in a well-known tertiary referral center with a presumably higher rate of secondary admissions of severely ill patients from surrounding hospitals, a factor that cortainly influenced the average $\mathrm{CT}$ score of all etiological groups.

\section{Conclusions}

We conclude that patients with alcohol-induced acute pancreatitis take a more severe course than the other etiological subgroups. These patients should be intensively monitored for respiratory insufficiency, since the incidence of necessity for artificial ventilation is high. Special attention should be given to the increased frequency of pancreatic pseudocysts in alcohol-induced acutc pancreatitis. suggesting a progression to chronic pancreatitis.

\section{References}

1 De Beaux AC. Palmer KR. Carter DC. Pacturs influencing morbidity and mortality in acute pancreatits: an analysis of 279 cases. (itu 1995; 37: 121-126.

2 Ranson JHC, Rifkind KM, Roses DF, Fink SD. Eng $K$. Spencer FC. Prognostic signs and the role of operative management in acute pancreatitis. Surg (ivnecol Obstet 1974: 1.39: 69-81.

3 Blamey SL. Imric CW, O Ncill J, Gilmour WH. Carter DC: Prognostic factors in acule pancrealitis. Cint 1984. 25: $1.340-1.346$.

4 Balihazar FJ, Rohinson DL. Megibow AJ. Ranson JHC. Acute pancreatitis: value of $C T$ in establishing progmosis. Radislogy 1990: 174: 331-336.

5 Ranson JHC. Etiological and prognostic lactors in human acule pancreatilis: a review. Am J Gasiroenterol 1982; 77 : $6.3 .3-6.38$.

6 Glazer C. Mann DV. United Kingdom guidelines lor the managenent of acutc pancreatitis. Gu 1998: 42 (stlppl 2): SI-SI3.

7 Garshick F. Segal MR. Wurobec TG, Salckin CMS. Miller MJ. Alcohol consuniption and chronic obstructive pulmonary disease. Am Res: Respir Dis 1989: 140: 373-378.

8 Lange P. Giroth S, Mortensen J, Appleyard M. Vyboe J. Jensen G. et al. Pulmonary function is influenced by heavy alcohol consumplion. Am Re' Respir Dis 1988: 1.37: $1119-1123$.

9 Uhl W, Iscnmann R, Curli G. Vogel R, Beger HG; Buchlet $M W$. Inlluence of etiolugy on the course and outcome of acule pancreatitis. Pancras [996: 1.3: 3.35-34.3.

10 Isenmann R. Buchler M. UhI W. Malferlheiner P. Marlini M, Beger HG. Pancreatic necrosis: an early finding in severe acute pancreatitis. Pancreas 1993: 8: 358-361. 